\title{
UTILIZANDO A ROBÓTICA PARA O ENSINO DE LÓGICA COMPUTACIONAL COM CRIANÇAS DO ENSINO FUNDAMENTAL
}

\author{
Paulo Calegari, LabTeC/UFSC, paulojagua@ hotmail.com \\ Tatiana Nilson dos Santos, PPGTIC/UFSC, tatiana.santos@posgrad.ufsc.br \\ Eliane Pozzebon, PPGTIC/UFSC, eliane.pozzebon@ufsc.br \\ Luciana Bolan Frigo, PPGTIC/UFSC, luciana.frigo@ufsc.br
}

\begin{abstract}
Resumo. O presente trabalho apresenta o desenvolvimento e aplicação de um dispositivo robótico voltado para o auxílio do processo ensino de lógica de computadores para crianças de 5 (cinco) a 7 (sete) anos. A aprendizagem para estas crianças é proposta de forma lúdica para que elas desenvolvam o raciocínio lógico, mesmo sem saber do que se trata, permitindo-lhes usar a imaginação. A robótica educacional é uma das áreas das Tecnologias de Informação e Comunicação (TICs) que vem ganhando cada vez mais espaço, pois é uma maneira atrativa para auxiliar no ensino de diversas áreas. Este projeto foi aplicado com crianças do primeiro ano do ensino fundamental de uma escola pública de Araranguá-SC e obtiveram-se resultados positivos, demonstrado pelo alto interesse dos participantes e estímulo no desenvolvimento do raciocínio lógico.
\end{abstract}

Palavras-chave: Robótica, Educação, STEM, Lógica de computadores.

\section{USING THE ROBOTIC LOGIC FOR COMPUTER EDUCATION WITH CHILDREN BASIC EDUCATION}

\begin{abstract}
This paper presents the development and application of a robotic device facing the help of computer logic educational process for children of five (5) to seven (7) years. The learning for these children is proposed in a playful way for them to develop logical thinking without even knowing what it is, allowing them to use their imagination. The educational robotics is one of the areas of Information and Communication Technologies (ICTs) that is gaining more space because it is an attractive way to assist in teaching various areas. This project was implemented with children in the first grade of elementary school to a public school in Araranguá-SC and yielded positive results, as demonstrated by the high interest of the participants and encouraging the development of logical reasoning.
\end{abstract}

Key-words: robotics, education, STEM, computational logic.

\section{Introdução}

As tecnologias educacionais podem ser compreendidas como uma aplicação de recursos tecnológicos que visam auxiliar no processo ensino-aprendizagem das crianças com o objetivo de torná-los mais criativo e motivador. Um exemplo são os softwares educacionais que variam de acordo com suas necessidades específicas, por exemplo, exercício e prática, simuladores, tutores, jogos sérios, entre outros (CALEGARI; POZZEBON, 2015).

Ainda há uma dificuldade em aderir às tecnologias como uma ferramenta de ensino capaz de proporcionar o mesmo (ou até mais) interesse em uma criança do ensino fundamental ou médio pelos estudos. Apesar disso, o uso delas em sala de aula 
vem crescendo cada vez mais, assim como o número de projetos que visam introduzir a computação para crianças. Projetos estes, que além de estimular gosto pela tecnologia, incentiva a formação profissional na área, já que o Brasil possui um grande déficit de profissionais no setor de TI, e que vem aumentando cada vez mais. $\mathrm{O}$ ingresso em cursos de áreas exatas, engenharias e tecnologia em geral não atende a demanda e a evasão é bem grande. (ESTADÃO, 2013).

Vale ressaltar que o ensino de computação, não se restringe à formação de profissionais na área, mas também pode desenvolver o raciocínio lógico necessário para o entendimento de diversas disciplinas como matemática, física, entre outras. Segundo Oliveira (2009),

"o não desenvolvimento desta capacidade nos alunos possivelmente trará reflexos no futuro, quando os mesmo passarem a se deparar com níveis cada vez mais elevados de situações em que precisam agir de forma lógica e organizada" (OLIVEIRA, 2009).

Foi utilizada neste trabalho a pesquisa qualitativa, que tem como objetivo principal interpretar o fenômeno que se observa, não existindo hipóteses préconcebidas, dá-se ênfase da indução. Em outras palavras, o pesquisador influencia e é influenciado pelo fenômeno pesquisado. (VILELA, 2009)

Desta forma, o presente artigo tem como objetivo apresentar os resultados obtidos na aplicação de um exercício, que utilizou como recurso tecnológico a robótica, aplicada para o ensino de lógica computacional em crianças na faixa etária de 5 (cinco) a 7 (sete) anos.

O artigo está organizado da seguinte maneira, na segunda seção é apresentada uma breve introdução sobre a robótica e os projetos de utilização da robótica educacional no Brasil; a terceira seção aborda a metodologia desenvolvida; na quarta seção é apresentada a proposta do exercício para o ensino de lógica e as atividades desenvolvidas; a quinta seção descreve os resultados da aplicação; a sexta seção apresenta as considerações finais do artigo e por fim, as referências utilizadas.

\section{Robótica}

Segundo Pires (2002), o termo robô vem do checo "robota" que significa trabalho forçado, e foi usado pela primeira vez em 1921 por Karel Capek em sua peça de teatro "Rossum's Universal Robots". Porém, foi na década de 40 que o termo "robótica" - como ciência - foi proposto por Isaac Asimov, em seu livro de ficção científica "Runaround", sendo que foi nesta obra que o autor criou as 3 (três) leis para a robótica (ROMANO, 2002).

A robótica como é conhecida hoje só se definiu como a disciplina que envolve conceitos de mecânica, eletroeletrônica e programação em meio ao século XX, com o desenvolvimento da microeletrônica. Segundo a definição analítica do Dicionário Aurélio (2015), robótica é o "conjunto dos estudos e das técnicas tendentes a conceber sistemas capazes de substituírem o homem em suas funções motoras, sensoriais e intelectuais".

Atualmente, o uso da robótica como artefato tecnológico tem crescido exponencialmente na medicina, nas indústrias bélicas, segurança e entretenimento bem como na educação. Esta última, refere-se a utilização da robótica como ferramenta de ensino, como um novo método de transmissão do conhecimento, a qual recebe o nome de Robótica Educacional 
A robótica educacional, ou pedagógica, é a basicamente a aplicação dos conceitos de robótica industrial, em um ambiente de aprendizagem que tem como objetivo promover o estudo de conceitos multidisciplinares. (TORCATO, 2012)

A ligação entre a robótica e a educação é bastante interessante, pois o robô, como elemento tecnológico, possui vários princípios básicos que podem ser abordados pela escola. Segundo Silva (2009), o robô mexe com o imaginário infantil, criando novas formas de interação com o mundo.

A robótica é, sem dúvida, uma área que desperta muita curiosidade independente da idade, e isso abre espaço para que o professor trabalhe diferentes conteúdos e estimule o interesse e a participação dos alunos nas atividades das aulas tradicionais.

\section{Metodologia}

Este projeto pode ser classificado como uma pesquisa aplicada, onde as atividades propostas foram realizadas com 20 (vinte) alunos da primeira série do ensino fundamental na Escola Básica Jardim das Avenidas, localizada na cidade de Araranguá$\mathrm{SC}$, todos com idade entre 5 (cinco) e 7 (sete) anos.

Além disso, segundo os conceitos trabalhados por Silva e Menezes (2005), esta pesquisa caracteriza-se como qualitativa a partir do momento em que passa a utilizar como instrumentos de análise, os sujeitos envolvidos e suas reações em relação aos objetos utilizados para a realização das atividades, que foram: o artefato robótico, o dispositivo móvel e o tabuleiro.

O projeto foi dividido em 4 (quatro) atividades, onde, com exceção da primeira atividade, todas elas trabalhavam conceitos de lógica de computadores, como por exemplo, recursividade e laço de repetição, apresentados na seção 3.2.

\subsection{Hardware e Software}

Para a realização desta atividade, foi desenvolvido um aplicativo para a plataforma Android, cuja função é que o usuário constitua um caminho lógico, com sequência dos movimentos que o artefato robótico deve realizar, para que o mesmo se desloque de um ponto inicial até um ponto final, cumprindo o objetivo de uma atividade proposta.

O aplicativo possui uma tela principal apresentado na Figura 1, com os campos de direção representados inicialmente pelos pontos de interrogação e na parte inferior os seguintes botões de comando:

- Conectar: parear o aplicativo com o dispositivo robótico via bluetooth.

- Enviar: enviar comandos com o trajeto para que o dispositivo robótico reproduza.

- Limpar: zerar campos para valores padrão. 


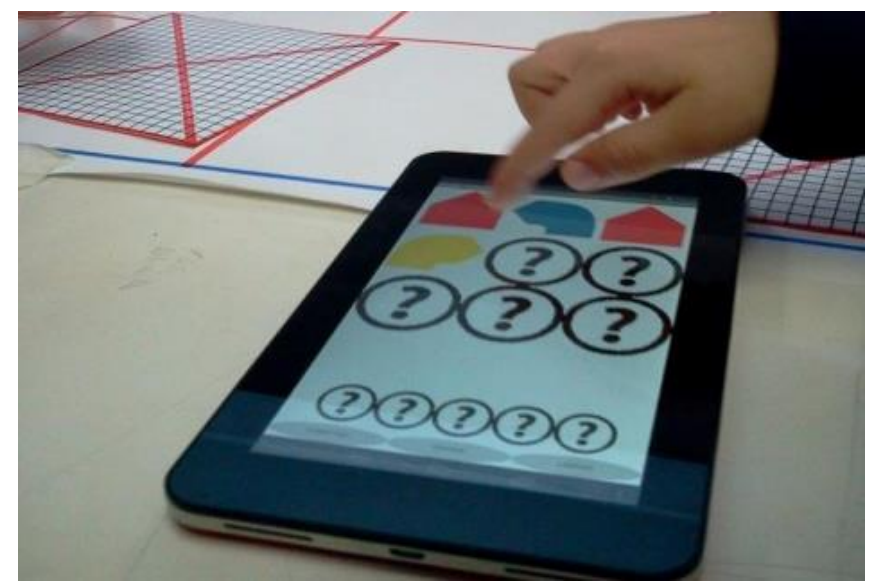

Figura 1 - Interface do aplicativo desenvolvido

O dispositivo robótico, como mostra a Figura 2 utiliza-se de um Arduino, mais precisamente o modelo Uno R3, um módulo expansivo motor shield para o controle dos dois motores de passo e um módulo bluetooth que faz a comunicação com um dispositivo móvel Android, que servirá como controle remoto.

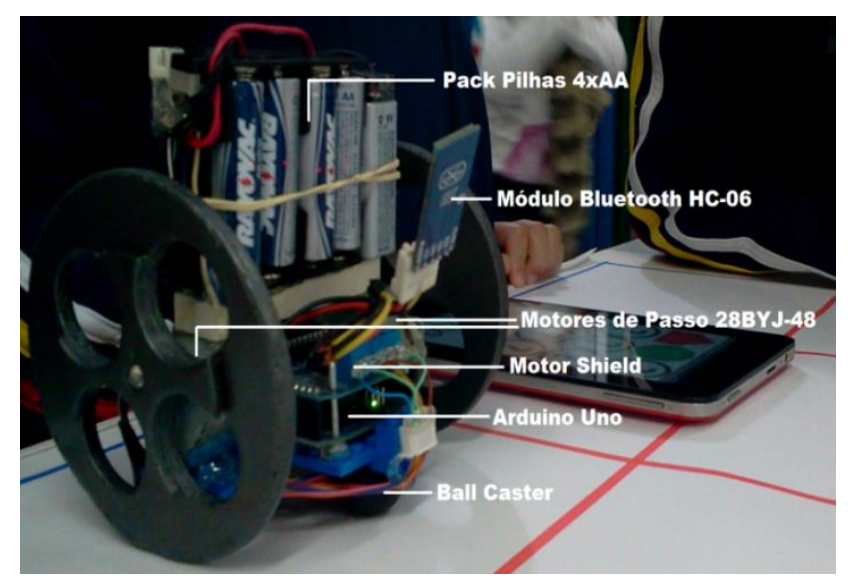

Figura 2 - Organização do hardware utilizado

O chassi do dispositivo foi montado com peças de LEGO, para dar suporte aos dois motores de passo, acomodar o Arduino acoplado ao motor shield e ao módulo bluetooth. A alimentação de todo circuito é feita por oito pilhas recarregáveis, e uma bateria, para maior autonomia do dispositivo.

\subsection{Atividades propostas}

As atividades lúdicas, de forma indireta, estão relacionadas com os conceitos básicos da lógica de computadores. Utilizando o método empírico de tentativa e erro a criança ordenará os passos necessários para realizar a atividade. Conceitos de laços de repetição e chamadas recursivas são compreendidos pela movimentação do robô.

Juntamente com a equipe de alunos foi feita uma apresentação do projeto e explicadas as tarefas que consistiam em 4 (quatro) atividades:

- Atividade 1: A primeira atividade teve como objetivo apresentar o robô e seu funcionamento básico.

Foi realizada a explanação da interface do aplicativo e simbologia presente. Todos os alunos realizaram essa atividade, controlando o robô de um ponto a outro no tabuleiro. A atividade durou aproximadamente quarenta minutos. 
- Atividade 2: Para a segunda atividade, o objetivo era planejar o trajeto no tabuleiro, desviando dos obstáculos.

Ou seja, a criança deveria observar o cenário com os obstáculos, conforme a Figura 3 e, tentar planejar todo o trajeto necessário para que o robô se desloque até um ponto final do tabuleiro, sem tocar em nenhum dos obstáculos.

Se acaso o robô colidisse com algum obstáculo, o dispositivo deve ser posicionado no início do tabuleiro e o aluno deveria reajustar o trajeto montado no aplicativo.
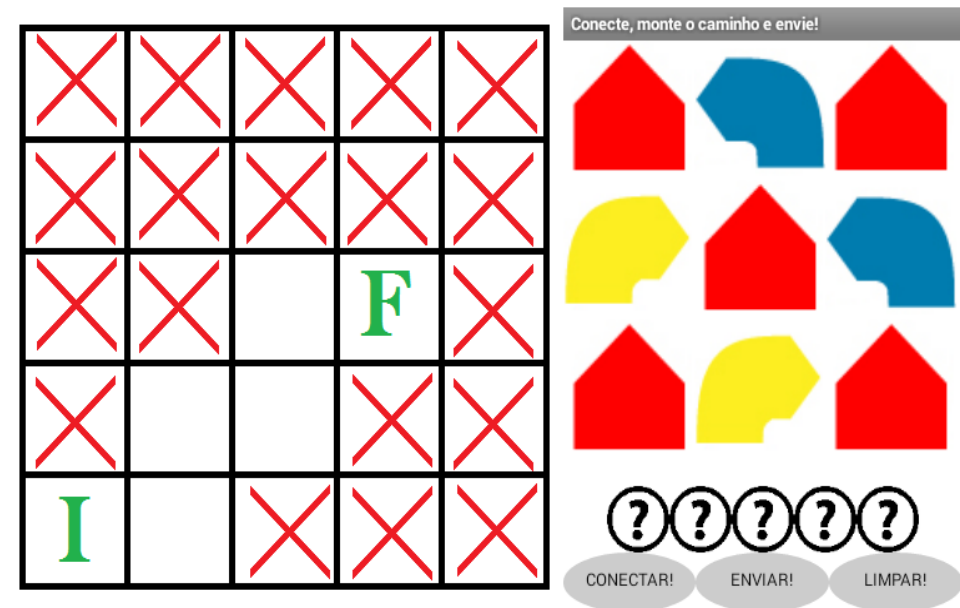

Figura 3 - Tabuleiro representado com o trajeto por meio dos obstáculos

- Atividade 3: A terceira atividade tem como objetivo ensinar o que é e como funciona o conceito de desvio de fluxo de execução.

No tabuleiro possuía alguns obstáculos em padrões repetitivos, exemplificados na Figura 4, como um zigue-e-zague, cujo objetivo era que o aluno tivesse que repetir os mesmos movimentos várias vezes para chegar ao fim do tabuleiro.
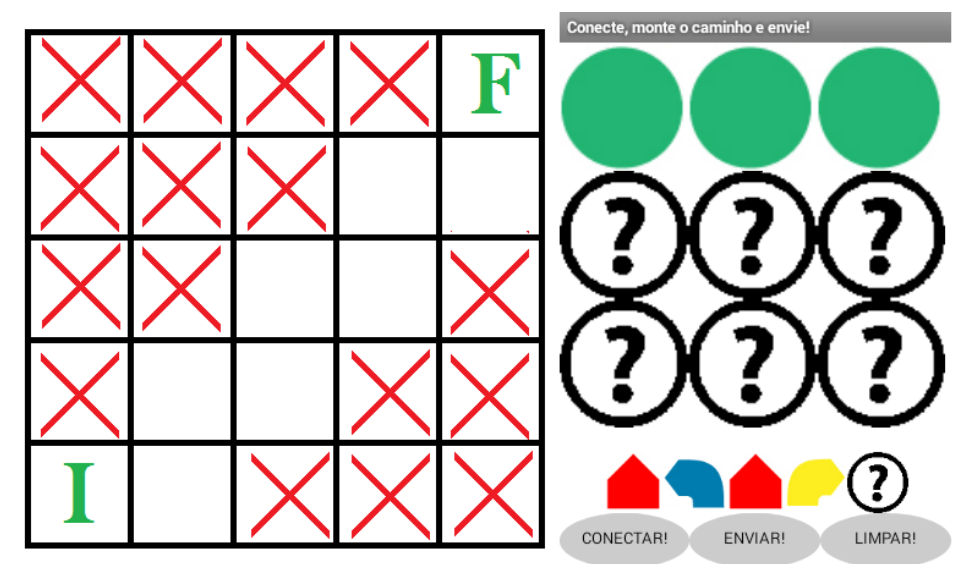

Figura 4 - Tabuleiro disposto com padrão de desvio de obstáculos.

Dessa forma, ao invés de repetir os mesmos movimentos várias vezes, é possível realizar várias chamadas desses movimentos por meio do desvio de fluxo, ou seja, desviar o fluxo de execução do programa para outro ponto especificado (VICHINSKY, 2008). 
Este método se assemelha a chamadas de sub-rotinas, que são blocos de instruções fora da rotina principal do programa, otimizando o caminho montado (VICHINSKY, 2008).

$\mathrm{Na}$ terceira atividade, das 20 (vinte) crianças que participavam das atividades, apenas 3 (três) conseguiram compreender a nova ordem de como os movimentos seriam executados. A partir daí, o desenvolvimento das tarefas foi focado nesses três alunos

- Atividade 4: Na quarta e última atividade foi apresentado o conceito recursividade, que em programação compreende o fato de uma função poder chamar a si mesma, direta ou indiretamente (SANTOS, 2013).

Inicialmente foi explicado como é possível fazer um desvio de fluxo dentro de outro desvio de fluxo, criando assim um movimento contínuo e repetitivo, conhecido por laço infinito (SANTOS, 2013).
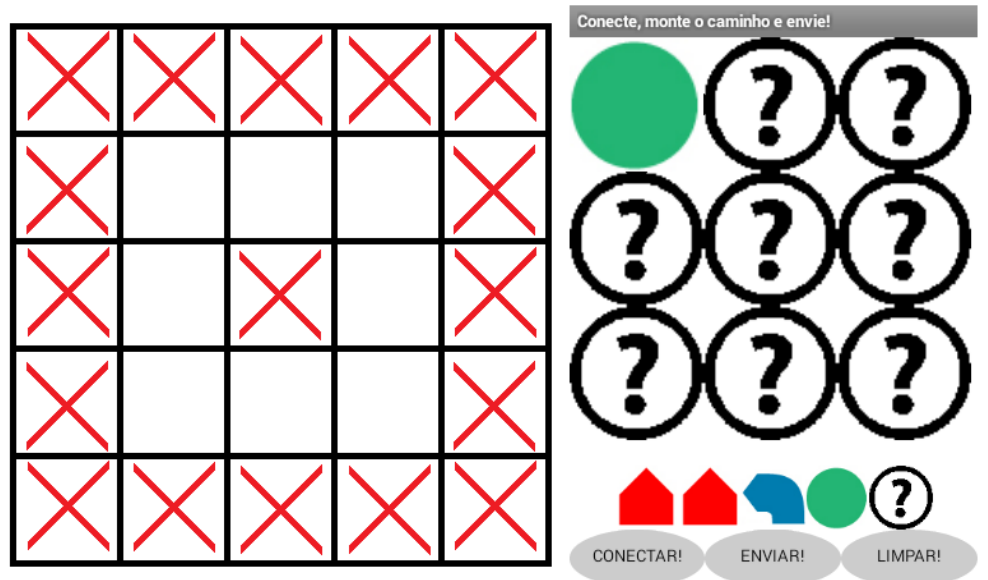

Figura 5 - Trajeto que fará o robô ficar andando em laço.

Assim, o aluno deve montar um caminho para que o robô fique andando em torno do tabuleiro, conforme Figura 5, em um laço de repetição infinito até que o botão reset seja pressionado.

\section{Resultados e Discussões}

Quando as atividades foram iniciadas, era nítida a euforia e entusiasmo por parte dos alunos ao saberem que iriam interagir com um robô. Umas das primeiras perguntas feitas por um aluno foi: "Vai ser tipo um videogame?" e logo em seguida outro respondeu "Não, é um carrinho de controle remoto!".

A principal dificuldade encontrada pelos alunos foi à distinção entre direita e esquerda, que dependendo do referencial (olhar o robô de frente ou por trás) resultava em movimentação oposta a desejada. Foi proposto então que o aluno ficasse sempre atrás do robô, para manter o referencial.

Todos os alunos controlaram o dispositivo com facilidade e acompanharam as orientações propostas. Foi observada a motivação das crianças e que o controle do dispositivo foi realizado corretamente, não havendo dificuldades com a coordenação motora. Nesta atividade os resultados foram satisfatórios considerando que todas as crianças entenderam o funcionamento básico do robô, explorando as funções de movimentar-se para frente, esquerda e direita. 


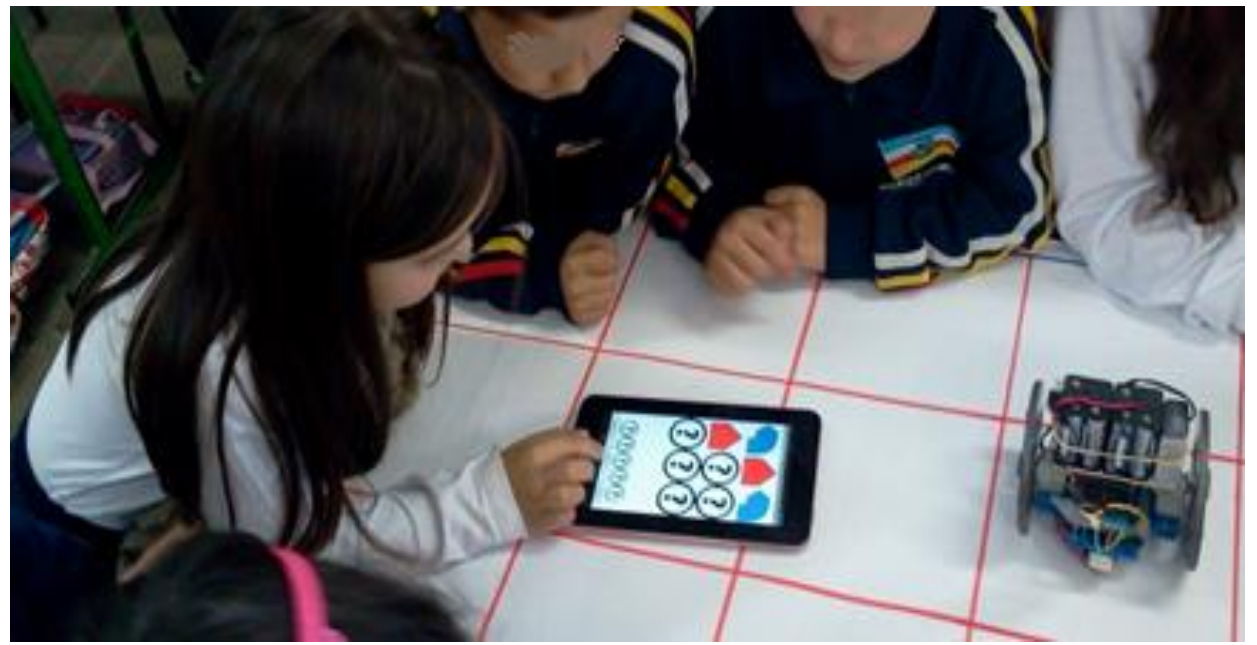

Figura 6 - Alunos realizando a primeira atividade proposta.

Um segundo fato que dificultava um pouco a realização da atividade é que havia muitos alunos aguardando e pedindo para controlar o robô, e enquanto isso tentavam acionar os botões do tablet que já estava sendo controlado por outra criança, o que gerava um pouco de tumulto no início. Após algum tempo os ânimos acalmaram-se e a atividade seguiu com mais tranquilidade. Praticamente todos os alunos já tinham convivência com tablets e smartphones no dia a dia, o que permitia a fácil interação com o aplicativo de controle do robô.

$\mathrm{Na}$ segunda atividade foram adicionados obstáculos ao tabuleiro, formando apenas um caminho por onde o robô deveria se deslocar. Inicialmente, a dificuldade foi um pouco maior pelo fato da metade das crianças não conseguirem concatenar mais do que dois ou três movimentos do robô no aplicativo. Foram então orientadas a verificar passo-a-passo, cada movimento necessário para concluir o trajeto. Com a tentativa e erro, e ajuda dos próprios colegas essa dificuldade foi sendo sanada e até o fim da atividade a maioria conseguia concatenar cerca de cinco a seis passos do robô corretamente, conforme a Figura 7.

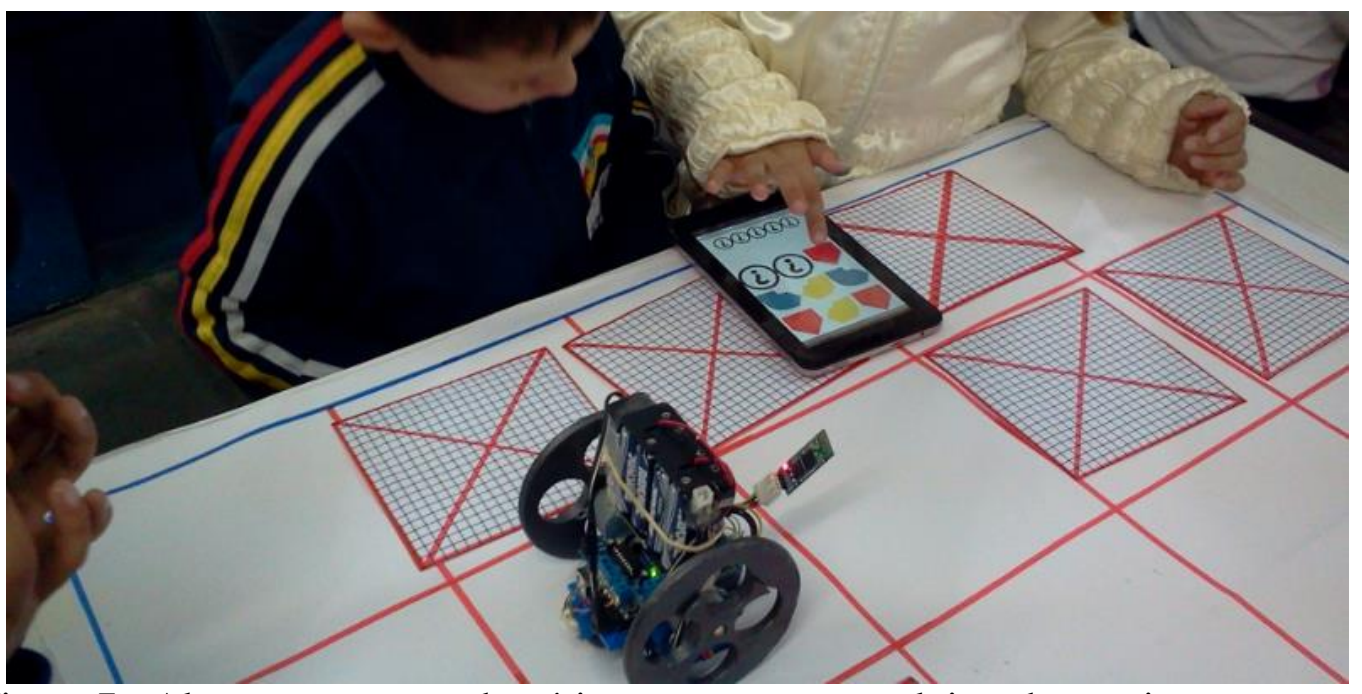

Figura 7 - Alunos concatenando vários passos para concluir todo o trajeto proposto.

Quando o robô saia do caminho proposto, o dispositivo voltava a sua posição inicial, o aluno era orientado a descobrir o erro existente e então reordenar os passos necessários. 
Esta atividade, ainda que lúdica, utiliza-se dos conceitos mais básicos de lógica, como ordenação correta do pensamento para solucionar um problema. Desde quando foi iniciada a atividade até seu término, observou-se um grande avanço na quantidade de passos corretos que as crianças conseguiam fazer o robô realizar, mesmo que em um curto período de tempo, cerca de 45 minutos.

A terceira atividade tem como objetivo ensinar o que é e como funciona o conceito de desvio de fluxo de execução. No tabuleiro constavam alguns obstáculos colocados em padrões repetitivos, como um zigue-zague, cujo objetivo era que o aluno tivesse que repetir os mesmos movimentos várias vezes para chegar ao fim do tabuleiro.

Dessa forma, ao invés de repetir os mesmos movimentos várias vezes, é possível fazer várias chamadas desses movimentos por meio do desvio de fluxo, semelhante a chamadas de sub-rotinas, otimizando o caminho montado.

Inicialmente foi explicado como funciona o desvio de fluxo, apresentando exemplos com o controle do robô, conforme a Figura 7.

Das 20 crianças que participavam das atividades, apenas três conseguiram compreender a nova ordem de como os movimentos seriam executados. A partir daí, o desenvolvimento das tarefas foi focado nesses três alunos.

Apesar do entendimento de como funciona o desvio, os alunos não conseguiram concatenar os movimentos complexos, como andar em zigue-zague, mas obtiveram êxito em fazer movimentos mais simples, como andar em círculos. Esta atividade durou cerca de 20 minutos, já que efetivamente poucos alunos participaram.

$\mathrm{Na}$ quarta e última atividade foi apresentado o conceito recursividade. Inicialmente foi explicado como é possível fazer um desvio de fluxo dentro de outro desvio de fluxo, criando assim um movimento contínuo e repetitivo. Como apenas três alunos conseguiram realizar a terceira atividade, os mesmos realizaram a quarta. A atividade durou aproximadamente 15 minutos e apenas um aluno conseguiu fazer o robô ficar andando em círculos repetidamente, os outros dois não conseguiram entender o funcionamento.

\begin{tabular}{|c|c|c|c|c|}
\cline { 2 - 5 } \multicolumn{1}{c|}{} & Resultados Positivos & Duração & Dificuldades & $\begin{array}{c}\text { Nível de } \\
\text { Interesse }\end{array}$ \\
\hline Atividade I & $\begin{array}{c}\text { Todos realizaram com } \\
\text { facilidade }\end{array}$ & $\begin{array}{c}40 \\
\text { minutos }\end{array}$ & $\begin{array}{c}\text { Distinção entre direita e } \\
\text { esquerda }\end{array}$ & Altíssimo \\
\hline Atividade III & $\begin{array}{c}\text { Atividade mais } \\
\text { desafiadora, maior } \\
\text { participação }\end{array}$ & $\begin{array}{c}45 \\
\text { minutos }\end{array}$ & $\begin{array}{c}\text { Concatenavam poucos } \\
\text { passos no começo }\end{array}$ & Altíssimo \\
\hline Atividade IV & $\begin{array}{c}\text { Maior complexidade } \\
\text { lógica. }\end{array}$ & $\begin{array}{c}20 \\
\text { minutos }\end{array}$ & $\begin{array}{c}\text { Poucos alunos } \\
\text { conseguiram }\end{array}$ & Médio \\
\hline minutos & $\begin{array}{c}\text { Apenas um aluno } \\
\text { conseguiu. }\end{array}$ & Baixo \\
\hline
\end{tabular}

Quadro 1 - Observações nas atividades realizadas

Supõe-se que essa dificuldade em realizar as últimas atividades esteja ligada a uma maior complexidade exigida no raciocínio lógico, o que ainda não é tão desenvolvido conforme a pouca idade das crianças (seis e sete anos). Outro fator que atrapalhava a concentração de quem tentava realizar as últimas atividades eram as 
outras crianças que desejavam brincar novamente, e acabam interrompendo o raciocínio dos demais.

Durante a aplicação das atividades, conforme Quadro 1, foram observadas as crianças interagindo e alguns dados foram coletados, como o nível de interesse dos alunos por uma atividade específica.

\section{Considerações Finais}

Neste trabalho foi realizada a aplicação e avaliação de tecnologias educacionais, como a robótica e dispositivos móveis em sala de aula, com alunos do primeiro ano do ensino fundamental, com crianças na faixa etária de 5 a 7 anos.

Após estudo de possíveis ferramentas a serem trabalhadas, foi desenvolvido um dispositivo robótico com o intuito de auxiliar no processo de ensino-aprendizagem da lógica computacional para crianças. A aplicação em sala mostrou que essas tecnologias tem altíssima aceitação por parte dos alunos, pois a aula se torna mais criativa e agradável. Vale ressaltar a importância do desenvolvimento do raciocínio lógico na fase da infância, pois ele é fundamental para a estruturação do pensamento e na resolução dos problemas diários.

Algumas iniciativas no Brasil e no exterior incentivam o uso da robótica educacional, como forma de motivar os jovens a seguirem carreiras na área de TI, já que muitos países - assim como o Brasil - vêm sofrendo com a falta desses profissionais.

Apesar da grande aceitação, algumas dificuldades foram encontradas na realização das atividades propostas. Uma delas é que algumas atividades exigiam muita concentração e raciocínio lógico da criança, que acabava muitas vezes perdendo o foco, por causa de distrações provocadas por outros alunos.

Conclui-se desta forma que o dispositivo robótico desenvolvido teve boa receptividade e atendeu a proposta do trabalho, que de forma lúdica permitiu o trabalho de conceitos de lógica computacional com crianças.

\section{Agradecimentos}

Os autores deste artigo agradecem toda a equipe do Laboratório de Tecnologias Computacionais (LabTeC) da Universidade Federal de Santa Catarina (UFSC) e aos alunos e professoras da Escola Básica Jardim das Avenidas de Araranguá/SC que colaboraram para a concepção e validação deste projeto.

\section{Referências Bibliográficas}

CALEGARI, P. F.; POZZEBON, E. Aplicação da robótica no ensino-aprendizagem de lógica para crianças. Trabalho de Conclusão de Curso, Universidade Federal de Santa Catarina, 2015.

DICIONÁRIO AURÉLIO. Significado de Robótica. Disponível em: <http://www.dicionariodoaurelio.com/ROBOTICA >. Acesso em: 30 de abril de 2015.

ESTADÃO (São Paulo). Déficit de profissionais de tecnologia se aprofunda no País. 2013. Disponível em: <http://economia.estadao.com.br/noticias/sua-carreira,deficit-deprofissionais-de-tecnologia-se-aprofunda-no-pais,147121e>. Acesso em: 30 de abril de 2015.

OLIVEIRA, E. N. A importância da lógica na aprendizagem. 2009. Centro Universitário Leonardo da Vinci - UNIASSELVI. 
PIRES, J. N. Robótica - Das máquinas gregas à moderna robótica industrial. Departamento de Engenharia Mecânica. 2002. Universidade de Coimbra.

ROMANO, V. F. Ed.: ROBÓTICA INDUSTRIAL - Aplicação na Indústria de Manufatura e de Processos. 2002; $1^{\text {a }}$ edição; Editora Edgard Blücher.

SANTOS, W. L. Algoritmos recursivos. Aula 1 - disciplina de Algoritmos e Estrutura de Dados II, UFGD/FACET, 2013.

SILVA, A. F. - RoboEduc: Uma metodologia de aprendizado com robótica educacional. Tese (Doutorado) - Universidade Federal do Rio Grande do Norte. 2009.

SILVA, E. L.; MENEZES, E. M. Metodologia da pesquisa e elaboração de dissertação. 4. ed. Florianópolis: UFSC, 2005. 138 p.

TORCATO, Paulo - O robô ajuda? Estudo de impacto do uso de robótica educativa como estratégia de aprendizagem na disciplina de aplicações informáticas $B$. Instituto de Educação da Universidade de Lisboa. II Congresso Internacional TIC e Educação. 2012.

VICHINSKY, R. Linguagem C: lição 7 - desvios. Linguagem C \& Inter-S, 2008.

VILELA, G. B. A pesquisa qualitativa. Metodologia da Pesquisa Científica, 2009. 